\title{
Large Risks and Limits of Insurability
}

\author{
by Baruch Berliner*
}

\section{Introduction}

The subject of this paper requires an analysis of the concepts "large risk" and "limits of insurability", since these cannot be defined in such a way that the definition will include all their properties. One reason for this is their subjective content. What is a large risk to one individual may not be a large risk to another. One risk may be insurable for one professional risk carrier and uninsurable for another.

The first section is devoted to an analysis of the concept "size of the risk", from which discussion we shall be able to understand what might be meant by the term "large risk".

In the second section we shall analyse the limits of insurability. In the third section we shall select some important specific subjects which interrelate large risks with the limits of insurability and show under what conditions large risks are insurable.

The concepts "large risk" and "limits of insurability" both have objective and very substantial subjective aspects. They cannot be defined, but only analysed.

In order to keep our considerations as general as possible we shall usually speak of applicants for cover instead of insureds, and of professional risk carriers instead of insurers. Applicants for cover can be real or corporate persons, or also insurers and reinsurers who apply for a partial cover of the risks they accept. Professional risk carriers can be insurance and reinsurance companies, insurance pools, pension funds and generally any corporation or group of corporations that accepts risks for a payment usually called a premium. Instead of "professional risk carrier" we shall often use the term "risk carrier".

If we wish to point out the more restricted meanings we shall use the terms "insured", "insurer" or "reinsurer". A loss or claim we shall also interpret as a realization of a risk.

\footnotetext{
* Swiss Reinsurance Company, Zurich.
} 


\section{An analysis of the size of a risk}

\section{A linguistic analysis}

A systematic linguistic analysis of the concept "size of a risk" may be based on a deterministic ot on a stochastic meaning. In colloquial English applicants for cover often interpret the deterministic and stochastic meanings in the following way:

(a) Size of a risk: a measure for a maximum size of a loss event.

(b) The risk regarded in probability terms: the risk increases as the probability of occurrence of a loss event becomes greater and the loss amount to be expected in the event of loss becomes higher.

From a risk-theoretical point of view, which should at least be the interpretation of risk of the professional risk carrier, the understanding of the size of a risk is different from and partly even contradictory to the colloquial interpretations described above. From the point of view of risk theory the concept "size of a risk" has a stochastic meaning. The size of a risk increases with growing deviations of claim results from the expected risk's claim amount during a certain period of time. The "size of a risk" is usually defined relative to the risk's expected claim amount.

Due to the law of large numbers the size of a risk relative to the risk's expected total claim amount during a period of time does not increase but decreases as the probability of occurrence of a loss event becomes greater. This is contradictory to the colloquial risk interpretation (b) above.

This colloquial, linguistically inspired, wrong risk interpretation (b) probably influences the intuitive risk behaviour of the population, which often does not cover its true insurance needs. As tests by Kunreuther and others have proved, people tend to cover themselves against risks with a high loss frequency and a low average loss amount, and show on the other hand no interest whatsoever in insurance if the probability of loss sinks below a certain individually variable threshold value. This threshold value is almost always at a point where insurance would still be recommendable on purely objective grounds.

We see that a linguistic analysis leads in the stochastic meaning to an interpretation contrary to risk-theoretical conclusions. Let us therefore concentrate on the deterministic linguistic analysis.

In order to illustrate possible ramifications of the deterministic meaning of the concept "size of a risk", we shall divide the first meaning (a) into two possible interpretations, one of which will be further broken down.

(a-1) The risk regarded as object the size of the risk depending on the size of the object. The value of the object corresponds to a measure of a maximum possible size of a loss event, i.e. to a maximum possible "loss of value" upon destruction.

(a-2) The risk as immaterial risk, the "value" of which depends for example on the estimated maximum compensation for pain and suffering in the event of loss.

Breakdown of $(\mathrm{a}-1)$

(a-11) Size of the risk = sum insured of the object.

(a-12) Size of the risk $=$ PML (probable maximum loss) or EML (estimated maximum loss) of the object. 
(a-13) Size of the risk = PML of a number of different risks subject to the same risk event as, e.g., the PML of an earthquake risk of an insurance company in a certain area.

(a-11) and (a-12) are different interpretations or measures of the maximum size of a risk object.

Bearing in mind the variety of deterministic meanings of the general concept "size of a risk" and at the same time the myriad of definitions of terms such as PML which describe only parts of this general concept, one can sense the immense number of interpretations to which such a general concept gives rise.

Common terms indicating the size of risks such as, for example, "large risk", "small risk", "bagatelle risk" are, of course, clearly connected with the abstract general concept "size of a risk" and, therefore, also share its fate as a conceptual Tower of Babel. They contribute to the familiar state of talking at cross purposes. Only rarely will two discussion partners understand exactly the same thing by the term "large risk".

It is, however, the case that terms like "large risk" or "small risk" are usually connected with absolute and not relative figures, i.e. they are expressed in money units and not in percentages.

In the stochastic meaning a "large risk" may be for example a risk with a large expected loss in case of a claim event or a risk with a claim distribution function having a large standard deviation etc.

In the deterministic meaning the "size of a risk" is characterized by a single number, an amount of money, which may be determined by one of the interpretations into which the concept "size of a risk" was broken down above. If this amount is large we speak of a "large risk" and if small of a "small risk". This linguistically used interpretation is partly justified by the fact that the larger a total loss is, the more it hurts the risk carrier; if we wish to quantify the painful consequences of a total loss we can say that they increase more than linearly as long as the risk carrier can bear them. A consequence of this fact is that the premium rate, i.e. the premium related to the size of the risk to be covered, should rise. Several reasons justifying this "antidiscount principle" in insurance are given in [1]. The "antidiscount principle" is derived from the exponential premium calculation principle, to be dealt with in Section III.1.

As may be seen from the short linguistic analysis, a uniform, clear definition of the concept "size of a risk" would not be generally accepted in practice and, as will be demonstrated below, would not make sense. Moreover, we have seen that the day-to-day interpretation of the concept "size of a risk" sometimes leads to understandings which are inconsistent with the findings of risk theory.

\section{The universality of the concept "size of a risk"}

The "size of a risk" can be dealt with from a linguistic, legal, economic, statistical or risk management point of view, from the point of view of the insurer, insured or legislator or from a macro- or micro-economic angle. Each viewpoint will partly intersect others but not encompass them completely. The various definitions of the concept may all be correct, but they all relate to different specific points of view [2]. 
The concept "size of a risk" may be compared with the surface of a sphere, the perspective or point of view with a location outside the sphere. The further away the location, i.e. the wider the perspective, the more surface can be seen and the more blurred the picture or notion will be. The example shows that several locations, i.e. perspectives, must be sought in order to get to know the entire surface of the sphere. The closer the locations to the surface of the sphere, the more locations must be sought to get a view of the entire surface, but the more distinct and detailed the view will be. It is therefore worthwhile to consider the concept from as many angles as possible in order to understand it thoroughly.

\section{Order of size}

The general concept of the size of a risk can be clearly divided and even classified by a quantifying property. By "clearly divided and classified" we understand that division and classification take place from each given perspective, i.e. from each point of view in the same way.

In the linguistic analysis we have already quantified the size of a risk from a stochastic as well as from a deterministic point of view. If the symbol $>$ is used to express the relation "greater than", the following ranking applies to each perspective: large risk $>$ major risk $>$ medium size risk $>$ small risk $>$ bagatelle risk. A major risk does not, of course, mean the same thing from each point of view. A major risk for an applicant for cover may be a small risk for the professional risk carrier, which is one of the reasons why insurance is necessary and insurance contracts are concluded. For the clarification and breakdown of the concept it is, however, important that in the case of each definition of the size of a risk a major risk be almost always more significant than a smaller risk for the risk carrier as well as for the applicant for cover.

Since the interpretations of the size of a risk relative to the size of another risk are subjective, borderline cases may exist in which a risk A may be judged by one individual as larger than a risk $B$ and vice versa by another individual. Such borderline cases need not, however, affect the possibility in general and practicality of a breakdown of the concept "size of a risk" into classes ordered by size.

In the classification of risks we refer only to persons who apply for cover and to risk carriers who have to decide upon the acceptance of cover, i.e. to persons or companies immediately confronted with the risk and its size. The opinions of persons with no relation whatsoever to the risk are excluded.

In the case of a breakdown of the concept "size of a risk", the terminology is clear and does not cause misunderstandings. By the order of size we have now also classified the term "large risk".

\section{The objective size of a risk}

The concept of risk contains two random elements with regard to probability:

(a) probabilities with which one or several losses are expected to occur during a certain period of time;

(b) the amount of loss expected upon occurrence. 
A loss is understood to be the realization of a risk. We can estimate the average time interval between two loss events and the average loss amount of a risk provided we have some knowledge of the risk and/or some loss experience at our disposal.

These estimates are all the more reliable, the better we know the risk, the higher the probability of loss occurrence per risk, the longer the period during which risk and loss can be observed and the higher the number of similar risks available for observation. The better the random elements a risk consists of can be estimated, the better we are able to evaluate the size of the risk objectively. The two random elements described above, loss frequency and loss amount, are risk related, objective facts insofar as they characterize each risk and distinguish it from other risks irrespective of the point of view from which it is examined.

In special cases we can derive uniquely and objectively the classes of distribution functions according to which the risk related random elements, loss frequency and loss amount are distributed and define the size of a risk as a function of the distributions' parameters. In other cases we can derive limit distribution functions for classes of risk.

(a-1) Suppose a sequence of claim events is a random process with the following properties:

(i) Events occurring in two disjointed time intervals are independent.

(ii) The number of events in a time interval $\left(t_{1}, t_{2}\right)$ is only dependent on the length of the interval $t_{2}-t_{1}$ but not on the initial value $t_{1}$.

(iii) Multiple events are excluded.

Then the probability of exactly $k$ claims occurring in a half closed time interval of length $t$ is Poisson distributed

$$
p_{k}(t)=e^{-\lambda t} \frac{(\lambda t)^{k}}{k !}
$$

there $\lambda t$ is equal to the expected number of claims [3].

Remarks 1. Risk objects destroyed by a loss event must be replaced. Otherwise the number of risks is reducing over time and property (ii) is no longer valid.

2. The reliability of the estimate of $\lambda$ increases with the time of observation $t$.

(b-l) Suppose each risk in a portfolio is restored after each loss event, the number of claims is Poisson distributed and we use "proper parameters". Under certain conditions which are plausible for important classes of risk we will not underestimate the expected total loss cost of a portfolio covering losses in excess of an amount $A>0$ if we use a Pareto distribution function for the amount of the single claim, and we will not overestimate it by using an exponential distribution function. Any distribution function with greater skewness than Pareto would lead to an overestimation, any one with smaller skewness than an exponential distribution function to an underestimation of the expected total loss cost. Thus the Pareto and exponential distribution functions are in a certain sense limit functions [4].

(b-2) Moreover, an extended Pareto class is a limit class which divides the claim amount distribution functions for which all moments exist from those for which all moments diverge [4]. 
The random elements can be eliminated by choosing for the "size of a risk" a deterministic definition as in Section I.1. in the linguistic analysis. A deterministic interpretation of the "size of a risk" ignores the random properties of a risk and is therefore more restrictive than a stochastic interpretation. If the size of a risk is defined deterministically by a certain not yet realized amount one risk cannot be distinguished from all other risks of the same "amount".

\section{The spread of risks}

In section I.2. we distinguished between linguistic, legal, economic, statistical and risk management points of view of the concept "size of a risk".

We now concentrate on the distinction between professional risk carriers, whose business is to accept cover, if possible, for a compensation called premium, and applicants for cover.

A professional risk carrier must take care to keep the probability of loss and ruin very small. He must see to it that he can not be hit too hard by a single loss event, i.e. he must follow certain rules with regard to the size of risks he is covering and get a wide spread of risks in his portfolio.

The spread of risks is all the better, the higher the number of similar independent risks and the longer the period observed. A risk carrier covering in each line of business a large number of equal or similar independent risks (homogeneous portfolios) which do not exceed a certain size can achieve a very good spread or balance, i.e. relatively small fluctuations of technical results from one year to another.

The lack of spread of risks compels the individual person - or makes it advisable for him - to take out insurance. For example, his house may be his only substantial property and risk object. Not insuring his house means for the individual taking a large risk, the outcome of which (loss occurrence or not) is unknown to him. He may be regarded as a carrier of a single risk, with the worst possible spread of risk if his uninsured house is his only important property object. It is therefore very advisable for him to transfer the risk to a professional risk carrier.

For the professional risk carrier, however, a loss occurrence of the same risk object may just be a realized risk which he has taken into account as a contribution to the balancing of results.

We observe dual properties of the concept "size of a risk". Subjectively seen one and the same risk may be a catastrophe risk for the insured and for the risk carrier only a medium size or small risk because of the spread of risks and losses in his portfolio (law of large numbers).

The aspect of spread gives a subjective understanding of the concept "size of a risk" and at the same time explains the usefulness of insurance.

\section{The cover and size of a risk}

The reserves of a professional risk carrier are usually much larger than those of an individual applicant for risk cover. Therefore, if a major risk of the applicant is only a small risk for the risk carrier, the latter can usually cover this risk against a premium such that the risk 
transfer is of positive utility to both parties. If this is not the case then the cover of the risk would either not be offered or not transferred by the applicant for the proposed premium. It is very important for and individual to bear in mind that, by purchasing a valuable object, he assumes a risk, the cover of which costs money. If he needs the cover but cannot raise the additional money for it, he should refrain from buying the object.

This again shows the dual properties of the size of a risk. Objectively seen, the purchase price of a risk object is equal to its selling price or to the "price" of its loss, respectively. Subjectively seen, the potential loss of the object may represent a major risk for the buyer and a small risk for the professional risk carrier. A risk transfer may therefore take place because of the subjective magnitude of the possible loss amount for the applicant for cover.

\section{The interdependence and size of risks}

Turning from the single risk (point of view of the applicant for cover) to a number of single risks (point of view of the professional risk carrier), we find, apart from the aspect of spread, a further typically pluralistic aspect, namely that of mutual dependence or independence of risks.

Risks are taken to be independent of each other if the objective probability situation of each risk is independent of its "environment" with other risks. In other words, there is no possibility of interaction (e.g. spreading of fire) in the case of the realization of independent risks.

If, however, a risk can be affected by the realization of other risks, then it is dependent on these other risks. The degree of this (often mutual) influence determines the degree of dependence of the risk on other risks. The degree of dependence or often interdependence of risks determines the accumulation risk, a term which is very common in insurance and particularly reinsurance. For a risk carrier the size of the accumulation risks is of utmost importance. It increases with growing interdependence.

The highest possible degree of dependence is reached when the realization of one risk necessarily leads to the realization of another risk. In this case we can speak of total dependence.

If a risk carrier's portfolio includes a number of risks which are totally dependent on each other, they can and should be regarded by the company as one risk. In the case of total dependence, the realization of one risk always causes a chain reaction of realizations of other risks. A multitude of totally interdependent small risks does not contribute to the balancing of the portfolio's result of a risk carrier, i.e. to improving the spread of risk of his portfolio.

The results of a risk carrier will be all the more balanced, the lower the degree of interdependence among the risks in his portfolio.

The transformation of a number of totally interdependent small risks into a single risk shows an interesting connection between the concept of dependence and the concept of the size of a risk. The size of a risk can depend aside from the dependence on other risks on other exogeneous factors like inflation, court decisions etc.

The interdependence of risks can represent a danger to the risk carrier, making reinsurance necessary or at the very least useful. 


\section{Splitting the size of a risk}

We have considered in Section I.7. the influence of the degree of interdependence of risks in a portfolio on the size of accumulation risks. There also exists, however, a most important, diametrically opposite aspect for professional risk carriers.

For reasons of convenience and usefulness let us consider any partial risk to be a risk on its own account, i.e. $x \%$ of a risk $(x \leqslant 100)$ is again a risk.

Consider a breakdown of a large risk $R$ into $n$ risks $R_{i}$, where $R=\sum_{i=1}^{n} R_{i}$ and each $R_{i}$ is a certain percentage of $R$. From an objective point of view all $R_{i}$ are mutually totally dependent on each other and the size of $R$ may be such that no single professional risk carrier can cover the risk. The risk, however, need not be uninsurable because of its size.

If $n$ risk carriers can be found, each of which covers one partial risk $R_{i}$, the whole risk $R$ is thereby covered.

The breakdown of a large risk $R$ into small risks and their distribution among different risk carriers which are independent of each other is an anti-accumulation procedure. The subjective size of part $i$ of risk $R$ is for the respective risk carrier the size of risk $R_{i}$. He has no interest in the objective size of the total risk $R=\sum_{i=1}^{n} R_{i}$. The part $R_{i}$ of a risk $R$ that a risk carrier will accept depends on the premium rate offered, on his capital and surplus, on internal directives, on his risk aversion etc.

In Section I.5. we mentioned that the cover of a large number of similar, independent risks leads to a good spread of risk of an insurance portfolio. Now we have seen the usefulness of the inverse procedure of getting a good "spread" of one large risk over many independent risk carriers.

By using any premium calculation principle which includes risk loadings and reflects risk aversion it can be easily shown that a risk carrier can be all the more competitive and cheaper the better the spread of risk in his portfolio is. On the other hand a large risk can be covered more easily and cheaply, the better it is spread over independent risk carriers.

Administrative and brokerage expenses set a practical limit to both these statements. If the atomization of risks in a portfolio or the atomization of a large risk over many independent portfolios goes beyond a certain limit the additional administrative and brokerage costs increase the premium beyond the reduction of the risk premium achieved due to the additional atomization over that limit.

\section{Risk aversion and the size of a risk}

Let us assume that a professional risk carrier already has a share in a major risk and that there is to be a change in the management. In the next year - the company's reserves and the premium rate for the risk having re mained unchanged - the risk carrier's share has to be determined anew. Depending on whether the new management is willing to take risks and eager to expand its business or is rather careful and reserved in its acceptance policy, it will increase or reduce the company's share in the major risk. Subjectively, it will look at the increased share $R_{i}^{\prime}$ or reduced share $R_{i}^{\prime \prime}$ as the same risk as the previous management considered the previous share $R_{i}$. This shows that, subjectively seen, the size of the risk depends not only on the existing reserves and the risk carrier's individual evaluation of the risk but also on his risk willingness. 
The decision of an individual whether or not to apply for an insurance cover depends on his willingness to take risks.

We shall not deal with the influence which legislation may have on an insurance company's acceptance policy, but merely mention that the factor of the size of risks should be considered by the legislator "as objectively as possible". To make certain covers at all possible and protect the safety of the insured the legislator should also consider the phenomenon of risk aversion.

The size of a risk, as seen subjectively, might influence the rate to be fixed by a risk carrier, whereas in the case of a given rate to cover a major risk the risk aversion, the amount of reserves as well as the costs and possibilities of reinsurance will have an effect on the share a risk carrier is prepared to accept. By the use of reinsurance, parts of the reinsurance company's reserves are made available to the risk carrier, enabling him to artificially increase his free reserves and accept objectively higher risks on gross account without assuming subjectively higher risks on net account. Insurer and reinsurer can be regarded as one combined risk carrier with substantially lower risk aversion but higher costs than the insurer alone. The existence of a reinsurance market usually influences the acceptability of large risks and the premium rate to the advantage of the applicant for cover.

The considerations in respect of the relationship between applicant for cover and risk carrier may also be applied to that between ceding company and reinsurer.

\section{Summary}

It has been demonstrated that the concepts "insurance" or, more generally, "risk transfer" and "size of a risk" are closely connected with each other. There even exists a causal connection between the two concepts. The size of a risk with all its objective and subjective, deterministic and stochastic aspects is an important cause of insurance. Insurance can partly be explained and defined on the basis of the concept "size of a risk". Spread and breakdown of risk are methods of insurance aimed at reducing the size of risk to ensure that a realization of a large risk can be borne without serious consequences.

The concept "size of a risk" cannot be fully covered by one definition. It can be analysed in its objective and subjective aspects and can be ordered in such a way that large risks are larger than medium size, small or bagatelle risks for nearly all risk carriers and applicants for cover. Taking this ranking as a starting point, we shall from now on only consider the partial set of risks with large size which we call "large risks" with respect to a certain professional risk carrier or an applicant for cover respectively.

Just as the size of risk is interesting for insurance, the large risks are specifically of interest for the insurability of risks.

\section{Limits of insurability}

\section{Objective versus subjective aspects}

The concept "insurability of risks" confronts us with similar fundamental problems to those associated with the concept "size of a risk". 
A general definition of the insurability of risks - however useful it might be - is not possible because of the subjective content and diversity of the concept. Instead of being defined it may, however, be examined by means of as clear and comprehensive an analysis as possible, which may in turn lead to important practical consequences [1].

Let us assume that a risk carrier is offered all the risks he is in principle prepared to write. Those risks that he would accept on the basis of his present portfolio and financial situation would represent his subjective area of insurability. He would refuse all other risks corresponding to his subjective area of refusal or uninsurability. The line separating these two areas would not contain any risk, as each risk would either be accepted or refused.

The objective area of insurability of a line of business is composed of all risks that would be covered by all professional risk carriers coming into consideration for the cover of risks in the respective line of business. The objective area of insurability is thus the intersection of all subjective areas of insurability, i.e. the largest area contained in all subjective areas of insurability. Similarly, the objective area of uninsurability is also the largest area contained in all subjective areas of refusal. Between the objective area of insurability and the objective area of uninsurability lies the objective transition zone or grey zone which includes all risks which some professional risk carriers would cover, others not.

If we imagine the objective area of insurability to be white and the objective area of uninsurability to be black, the grey zone leads from the white area over ever darker grey shades to the black area. The lighter the shade, the closer the respective area is to the area of insurability and the higher the degree of insurability.

The shades of the grey zone indicate the degree of insurability of the risks, i.e. the percentage of professional risk carriers who would cover the risks within the area of a certain shade. The higher the percentage, the lighter the shade.

The very study of the shades within the grey zone leads to a comprehensive analysis of the limits of insurability.

With the introduction of subjective and objective areas of insurability we have focussed our attention exclusively on the opinion and the behaviour of professional risk carriers.

In the next section we shall show that neither the risk objects themselves nor the opinion of non-professional carriers of own risks are suited for the determination of the limits of insurability of risks.

This is a major distinction from the analysis of the concept "size of a risk", where we attached the same importance to the subjective opinion of the applicant for cover as to that of the professional risk carrier. However, we had the implicit restriction that a person's opinion of the size of a risk only became relevant from the moment when he applied for its cover.

\section{Basis of analysis - applicants for cover versus professional risk carriers}

The following may be used as a basis of analysis:

(a) the objects to be insured;

(b) the opinion of the professional risk carriers interested in principle;

(c) the opinion of all risk carriers. 
Alternative (b) we used already in the last section to define the subjective areas of insurability or uninsurability respectively. We shall see that the two alternatives (a) and (c) do not allow a comprehensive or precise analysis of the concept of insurability and lead to unnecessary complications of analysis.

If we choose the objects to be insured as a basis of analysis, all risks which do not consist of definable objects such as, for example, the various liability risks, pain and suffering, etc., can not be examined as to their insurability. If we consider a risk, e.g., a certain factory with a fixed PML, which a risk carrier would insure under certain conditions and another risk carrier would not insure under the same conditions, the question arises whether this risk is insurable or not. If we only consider the object and not the opinion of potential risk carriers, the answer to this question is arbitrary and unsatisfactory.

Like the professional risk carrier, each individual person or legal entity has its own idea about the insurability of its risks and the necessity of having them insured. Why should we not consider the opinions of all these individuals about the insurability of risks as well?

We may distinguish two categories of risks: those for which cover is sought externally or is legally required and all other risks. An analysis of the latter would in practice be impossible because of their large quantity and because one is not aware of the existence of many of these risks; in addition, it would not be very interesting for the following reasons:

External cover of known risks is often not sought because they can easily be borne - such risks would belong to the objective area of insurability - or because it is known a priori that no professional risk carrier would cover them - these risks would fall under the objective area of uninsurability. When examining the insurability of risks we are in the first place interested in analysing the grey zone, which is why the risks for which no cover is sought can be excluded from insurability considerations without reducing the informative value to any major extent.

As far as the insurability of those risks for which external cover is sought is concerned, the opinion of those asked to assume a risk under certain conditions, i.e. of the professional risk carriers, is decisive and not the opinion of those wishing to cede the risk, i.e. the opinion of the applicants for cover.

If the insurability of risks were primarily related to private persons or legal entities, a risk would be defined as insurable if the applicant for cover found a single risk carrier who would grant the requested cover. The opinion of other potential risk carriers would not be of any interest to him. In such a case we objectify the definition and include the grey zone in the area of insurability. The resulting exclusion of the concept "grey zone" - which is decisive for the determination of the degree of insurability - from the analysis of insurability would have serious consequences.

From these considerations we conclude that the opinion of professional risk carriers who are in principle interested in providing the cover should be taken as a basis of the analysis of insurability of risks [1] [5].

\section{Idealistic versus pragmatic approach}

When examining the insurability of risks one may concentrate on the question of what risks should be insured or on the question of what risk can actually be covered. The first question leads to the idealistic, the second to the pragmatic approach. 
The basic difference between these two approaches is illustrated by means of the following example:

Underrated risks should not be insured but are constantly covered in practice because risk carriers seek to gain, maintain or defend market positions. "Professional sinning" in this respect increases on the free market as competition grows. Risks may be deliberately underrated for some time, if the risk carrier hopes to make the business profitable in the long run by improving the terms.

An analysis of insurability should adopt the pragmatic approach; however, the principles, rules of conduct and recommendations resulting from the analysis for the professional risk carrier rather suggest the idealistic aspect [1]. The idealistic aspect should never be forgotten and indeed should play a decisive role in the long term planning and marketing policy of a professional risk carrier because it contains - as opposed to the pragmatic approach - checks to prevent gliding off toward disaster.

\section{Confrontation of the insurance industry and the individual insurer with the limits of insurability}

The insurance industry as a whole is increasingly confronted with risks where for reasons of principle and capacity doubts arise as to whether they can and should be covered. This increase of risks at the limits of insurability is due to growing social and accumulation problems, advancing technology and concentration of values, increased complexity and exposure of numerous risks.

Growing competition is causing professional risk carriers to accept risks which they would formerly have refused, i.e. to increase pragmatically their area of insurability. Such a dangerous development can be observed, for example, in the case of political risks, where cover is becoming more and more extensive.

The aspect of competition leads us from the insurance industry to the individual insurer, who is confronted with the question as to whether he should cover certain risks offered at certain terms against a certain competitive premium. The alternative to the pragmatic approach would often be loss of business. The risks which he refuses to cover are placed in the respective professional risk carrier's subjective area of uninsurability.

\section{The subjective net and the subjective gross insurability area}

The net insurability area is composed of the risks which the risk carrier would accept without the possibility of ceding part of them to reinsurers, coinsurers or pools. The gross insurability area, which is substantially bigger, consists of all risks he can accept thanks to the possibility of ceding part of them to other risk carriers. $\mathrm{x} \%$ of a risk is taken to be a different risk than $\mathrm{y} \%$ or $\mathrm{z} \%$ of the same risk. The former may, for example, be insurable on a net basis, the second may be uninsurable on a net basis but insurable on a gross basis and the latter uninsurable on a gross basis.

Improved portfolio balance under the retention, the reduction of the probability of loss, insolvency or ruin and higher profit expectations are closely connected with the subjective net area of insurability. Image, competitiveness and satisfaction of customer needs are closely 
linked with the subjective gross area of insurability. A suitable reinsurance policy of the professional risk carrier may serve as an extremely effective possibility of extending both the net and gross areas of insurability [6].

\section{The criteria of insurability}

The area of insurability, grey zone and area of uninsurability which were described in Section II.1. are not just abstractions, but can be regarded as areas in a multidimensional Euclidean space, the axes of which are insurability criteria. All but one of the following criteria can be quantified and plotted in such a way that the area of insurability is concentrated around the origin, surrounded by the grey zone which in turn is surrounded by the area of uninsurability, as shown in detail in [1].

Each risk corresponds to one point in the geometric model. If this risk is unchanged, the corresponding point does not change. The allocation "risk $\rightarrow$ point" is independent of time. On the other hand, the boundaries of the objective and subjective insurability areas and the shades in the grey zone may change in the course of time as a result of improved risk information, changed risk assessment, new business policy, mergers, new reinsurance covers or other changes. A point in the subjective area of uninsurability may move into the subjective area of insurability as a result of expanding limits of insurability in the course of time [1].

The following criteria which can also be interpreted as dimensions of insurability have to be gone through by the professional risk carrier individually like a checklist when assessing the insurability of a risk:

a. Randomness (of the loss occurrence)

b. Maximum possible loss

c. Average loss amount upon occurrence

d. Average period of time between two loss occurrences

e. Insurance premium

f. Moral hazard

g. Public policy

h. Legal restrictions

i. Cover limits

The first five of the above-mentioned criteria belong to the actuarial-mathematical area, the sixth to the empirical area, the seventh to the ethical-moral area and the last two to the legal area. Criteria (e), (f), (g) and (i), in particular, affect the commercial area.

The criteria are not independent of each other - the average loss, for example, can never be bigger than the maximum possible loss - but the system of criteria is concise and practically complete, i.e. the insurability of practically each risk coming into consideration can be clearly defined both subjectively and objectively by the system or criteria. None of the nine criteria is superfluous, i.e. no criterion can be replaced by any combination of the other eight criteria. 
A criterion is satisfied if it confirms the insurability of a risk and a risk is uninsurable for a professional risk carrier if at least one criterion is not satisfied [1].

\section{Some examples of interrelations between the concepts "large risks" and "limits of insurability"}

The connection between the two concepts was carried out in Section II.6. by the introduction of the criteria of insurability, some of which are linked to the concept "size of a risk" and thus, because of the possibility of ranking risks by magnitude, to the concept "large risks" with respect to the professional risk carrier.

\section{The antidiscount principle}

Denote the capital and surplus of a risk-averse professional risk carrier by $S$, a risk for which a cover is applied for by $x$ and the premium for the cover of the risk by $P$. Pdepends on $S$, the utility function of the risk carrier and the distribution of $x$.

Suppose that the utility function is of an exponential type

$$
u(S)=\left(1-e^{-a s}\right) / a, 0<a<\infty
$$

and that the premium $P$ is obtained as a solution of the equation

$$
u(S)=E[u(S+P-x)]
$$

(2) describes the premium calculation principle of zero utility, i.e. the risk carrier is only ready to accept a risk, if this acceptance does not reduce his expected utility.

(2) is a principle of fairness expressed in terms of utility of monetary units.

If the risk carrier's utility function is exponential, i,e, if (l) is fulfilled, we speak in case of (2) of the exponential premium calculation principle. It can be shown that the exponential premium calculation principle is the only one used in practice which satisfies certain five important properties [7, Chapter 5]. Results derived from this principle are therefore essential.

Using (1) we can easily derive an explicit solution for equation (2):

$$
P=\frac{1}{a} \cdot \log \left[E\left(e^{a x}\right)\right] .
$$

Gerber has shown that

$$
\frac{d P}{d a}>0[7] \text {. }
$$

The larger the risk carrier's risk aversion $a=-u^{\prime \prime}(S) / u^{\prime}(S)$, the larger is the premium.

This is an important property which reflects market reality and is satisfied by the exponential premium calculation principle. 
Suppose that $z$ is a certain percentage of a risk $x$ covered by a risk carrier with risk aversion $a$. Under what condition will he be ready to increase his participation from $z x$ to $c \cdot z x$, where $c>1$ is a constant?

From (3) follows:

$$
\begin{aligned}
& \bar{P}=\frac{1}{a} \log \left[E\left(e^{a(c z x)}\right)\right]=\frac{c}{a \cdot c} \log \left[E\left(e^{(a c) z x}\right)\right] ; \\
& \bar{P}>\frac{\bar{P}}{c}>P ;
\end{aligned}
$$

because of (4) and $c>1$, i.e.

$$
\bar{P}>c \cdot P
$$

The risk carrier will accept a participation increased by factor $c>1$ if the premium offered exceeds $\bar{P}$ in (5), i.e. increases at least by a factor $\bar{P} / P>c$. From (6) we learn that risk aversion leads in case of an exponential premium calculation principle to a premium rate, i.e. to a premium relative to exposure, which increases with increasing exposure to the same risk object.

This result can be generalized by studying other premium calculation principles of riskaverse risk carriers and premium rates for different exposures to different risk objects. in $[1])$.

(6) leads to a rule of conduct which may called antidiscount principle (principles 15 and 16

We see that the insurability of large risks is not only connected with the insurability criterion "maximum possible loss" which is one interpretation of the risk exposure, but also with the insurability criterion "insurance premium". The larger the risk, the more expensive should be the premium rate and the closer it comes for a given premium rate to the limits of insurability of ever more risk carriers who do not follow a dangerous and illogical "pragmatic" underwriting policy.

\section{Large risks and their optimal distribution among risk carriers}

Many authors have treated the problem of Pareto optimal distributions of risks among risk carriers or funds which lead to Pareto optimal risk exchanges such that no risk carrier can improve his utility any more on the set of treaties covering a set of risks [8], [9], [10]. An optimal distribution of risks among risk carriers leads to an optimal use of available capacity for a given premium and increases the insurance market's area of insurability for large risks.

G. Benktander has studied the case where a risk-averse insurance and reinsurance company try to find an arrangement which leads to a substantial reduction of the variance. If the ceding company's portfolio variance is before reinsurance $V_{B}$ and after reinsurance $V_{A}$ and the corresponding variance transferred to the reinsurer $V_{R}$ Benktander demands that

$V_{B}-V_{A}-V_{R} \gg 0$ and

$a_{C}\left(V_{B}-V_{A}\right)-a_{R} V_{R}>0$, where

$a_{C}$ and $a_{R}$ are the ceding company's and reinsurer's risk aversions [11]. 
It is proved that it is always possible to find reinsurance arrangements that satisfy the two inequalities above [11]. If we measure the size of a risk by the uncertainty associated with it which is one possible interpretation, as we have seen in Sections I.1 and I.5 - it is therefore always possible to reduce the largeness of a risk by an appropriate reinsurance arrangement which reduces its variance.

An optimal distribution of a risk among risk carriers is splitting up the size of a risk in an anti-accumulation procedure - as described in Section I.8. - in an optimal way which may make very large risks insurable under reasonable conditions.

\section{Large risks and moral hazard}

Moral hazard refers to the tendency of insurance protection to alter the insured's motive

a) to prevent loss;

b) to create loss;

a) was analysed by Shavell [12], b) was pointed out by Berliner [1].

Both a) and b) affect the size of the risks of the applicant for cover, the expenses for the insurer and the proposed cost of coverage for the insured. Combining the problems of risk and insurance with asymetric information [13] leads to two major problems, namely "adverse selection" and "moral hazard". Moral hazard problems arise from imperfect information concerning the motives and actions of applicants for cover. As a fundamental tendency we state that the better the insurance protection the less incentive individuals have to avoid insured events, because the less they bear the full consequences of their actions [13].

To cope with the phenomenon of "moral hazard", which is also one of the nine criteria of insurability introduced in Section II.6., the professional risk carrier may therefore offer incomplete coverage against loss and "observe" the care taken to prevent loss. Shavell has shown that the optimal insurance policy under moral hazard offers partial rather than full coverage when care is not observed by the insurer, if the cost of taking care is - for the applicant for cover - sufficiently low and his utility function is concave; i.e. if it is not very costly to take care, then the incentive effect due to partial coverage should be strong [12].

The risk carrier can introduce a bonus-malus system based on experience rating, thus creating an incentive for the insured to take care. Expenditures by the applicant for cover to reduce moral hazard are often rewarded by the risk carrier with a premium reduction in such a way that the reduction of moral hazard is of positive utility for both parties. Last but not least a professional risk carrier can reduce moral hazard by cover limits which exclude claim payments under certain conditions. We meet here an indirect connection between large risks and the insurability criterion of "cover limits" via the criterion of "moral hazard".

Bearing in mind that uncertainty can be a measure for the size of risk, we conclude than that uncertainty of a risk for a professional risk carrier can stem from:

(a) hazards inherent in the risk;

(b) lack of information on the risk;

(c) moral hazard, i.e. imperfect information on the applicant for cover. 
We have focussed in this section on moral hazard and mentioned several ways to cope with that problem. Reducing moral hazard for large risks means a reduction of the risk's size for the professional risk carrier and may imply a way to find cover for otherwise uninsurable risks.

\section{Concluding remarks}

If large risks can not be fully covered on the insurance market because of their size or the uncertainty inherent in them, they are pragmatically interpreted as objectively uninsurable. They can be in the area of uninsurability because one or several criteria of insurability such as "randomness", "maximum possible loss", "insurance premium", "moral hazard" or "cover limits" are not satisfied as a result of the risk's largeness. The concepts "large risks" and "limits of insurability" are interrelated both from subjective and objective aspects through the criteria of insurability.

In the last chapter we illustrated such interrelations with some important examples and indicated steps to make large risks insurable.

\section{REFERENCES}

[1] B. Berliner: "Limits of insurability of risks", Prentice-Hall, 1982.

[2] B. Berliner: "Einige Betrachtungen zum Begriff der Grösse eines Risikos", Zeitschrift für Versicherungswesen, Rückversicherungssonderheft, November 1976.

[3] R.E. Beard, T. Pentikäinen, E. Pesonen: Risk Theory, Methuen \& Co. Ltd., London EC4, 1969.

[4] G. Benktander: "Schadenverteilung nach Grösse in der Nicht-Leben-Versicherung", MVSV 70. Band, Heft 2, 1970.

[5] B. Berliner: "Gedanken zur Versicherbarkeit und zur Schiedsgerichtsklausel", Mannheimer Vorträge air Versicherungswissenschaft, Band 28, 1983.

[6] B. Berliner: "Einige Gedanken zur Versicherbarkeit und Rückversicherung", Zeitschrift für Versicherungswesen, November 1982.

[7] H.U. Gerber: "An introduction to mathematical risk theory", S.S. Huebner Foundation Monograph Series, Monograph No. 8, 1979.

[8] K.H. Borch: "The safety loading of reinsurance premiums", Scandinavian Actuarial Journal, 1960.

[9] H.U. Gerber: "Pareto optimal risk exchange and related decision problems", Astin Bulletin, Vol. 10, Part 1, 1978.

[10] H. Bühlmann, W.S. Jewell: "Optimal risk exchanges”, Astin Bulletin, Vol. 10, Part 3, 1979.

[II] G. Benktander: "A note on optimal reinsurance", Astin Bulletin, Vol. 8, Part 2, 1979.

[12] Steven Shavell: "On moral hazard and insurance", Quarterly Journal of Economics, 93, 1979.

[13] J.E. Stiglitz: "Risk, incentives and insurance: the pure theory of moral hazard", The Geneva Papers on Risk and Insurance, Vol. 8, No. 26, 1983. 